\title{
Conhecimentos mobilizados por uma professora de Matemática de estudantes surdos
}

\author{
Knowledge mobilized by a Mathematics teacher of deaf students
}

\author{
Flavia Roberta Porto Teófilo \\ Armando Traldi Júnior
}

\begin{abstract}
Resumo: Neste artigo são discutidos os conhecimentos mobilizados por uma professora de Matemática, a partir de uma Trajetória Hipotética de Aprendizagem (THA), para um grupo de estudantes surdos. $O$ artigo tem como fundamentação teórica tanto as pesquisas sobre THA no ensino de Matemática em uma perspectiva construtivista, quanto as que tratam dos conhecimentos do professor. Os resultados indicam que a THA pode ser utilizada como instrumento para verificar os conhecimentos mobilizados pelos professores. Em relação ao professor de surdos, é possível afirmar que o conhecimento da cultura e das especificidades destes estudantes, dos recursos visuais, do pedagógico, do conteúdo específico e da língua de sinais articulada com a língua portuguesa são essenciais no processo de ensino.

Palavras-chave: Conhecimento do professor. Estudante surdo. Trajetória Hipotética de Aprendizagem. Educação Matemática.

Abstract: In this article the mobilized knowledge of a Mathematics teacher is discussed from a Hypothetical Trajectory of Learning (HTL) to a group of deaf students. The article has a theoretical based researches about the usage of the HTL in the teaching of Mathematics in a constructive perspective as well as about relation to the teacher's knowledge. The results indicate that the HTL may be used as a tool to verify the mobilized knowledge by the teachers. Concerning the teacher of deaf students, visual and pedagogical

Flavia Roberta Porto Teófilo Mestre em Ensino de Ciências e Matemática do Instituto Federal de Educação, Ciência e Tecnologia de São Paulo (IFSP). Professora da Secretaria Municipal de Educação de São Paulo (SME). São Paulo, Brasil. $M$ fla.porto@gmail.com

Armando Traldi Júnior Doutor em Educação Matemática (PUC-SP). Professor do Programa de Pós-Graduação em Ensino de Ciências e Matemática do Instituto Federal de Educação, Ciência e Tecnologia de São Paulo (IFSP). São Paulo, Brasil. $\bowtie$ traldir@gmail.com

Recebido em 20/01/2019 Aceito em 15/02/2019 Publicado em 01/05/2019
\end{abstract} resources, specific content and the Sign Language joined with the Portuguese Language are essential in the learning process.

Keywords: Teacher's knowledge. Deaf student. Hypothetical Trajectory of Learning. Mathematics Education.

\section{Introdução}

Este artigo é parte de uma pesquisa de Mestrado Profissional, realizada com a participação de uma professora de Matemática de uma escola de Ensino Fundamental bilíngue para surdos (EMEBs). A investigação fez parte do projeto "Educação Matemática para estudantes surdos", desenvolvido pelo Grupo de Pesquisa em Educação Matemática e Profissional, do Instituto Federal de Educação, Ciência e Tecnologia de São Paulo (IFSP), que tem como objetivo compreender os conhecimentos do professor de Matemática de estudantes surdos. 
Neste artigo, apresentamos resultados da pesquisa realizada com o objetivo de compreender conhecimentos mobilizados por uma professora de estudantes surdos por meio de uma Trajetória Hipotética de Aprendizagem (THA) sobre função afim. Segundo Simon (1995), as THA consistem em objetivos para a aprendizagem a partir de tarefas matemáticas que serão usadas para promover o ensino, bem como o levantamento de hipóteses de todo processo vivenciado pelos estudantes e professor.

Em relação ao conhecimento profissional dos professores, nos apoiamos em estudos de Shulman (1987), que revelam que os conhecimentos do professor são essenciais no processo de ensino. 0 autor traz sete categorias de conhecimentos para o ensino: conhecimento do conteúdo, conhecimento pedagógico geral, conhecimento do currículo, conhecimento pedagógico do conteúdo, conhecimento das características cognitivas dos alunos, conhecimento dos contextos educacionais e conhecimento dos objetivos educacionais e de seus valores, além de suas bases históricas e filosóficas.

Para discutir o conhecimento do professor de estudantes surdos, nos apoiamos em Campello (2008), que afirma não haver uma sistematização de um conhecimento especializado para nortear a formação de docentes que irão atuar com estudantes surdos. A autora propõe a Pedagogia Visual, afirmando que as práticas docentes dirigidas a estes estudantes devem contemplar a exploração de diversas imagens nos processos de ensino e de aprendizagem a fim de garantir uma aprendizagem significativa para os estudantes.

A escolha do objeto matemático "Função Afim", para elaboração da Trajetória Hipotética de Aprendizagem, se deu por se tratar de um conteúdo possível de ser aplicado em diferentes situações do cotidiano, possibilitando uma maior compreensão do estudante em relação a situações que envolvem variação. Além disso, de acordo com os Parâmetros Curriculares Nacionais para o Ensino Médio - PCNEM (BRASIL, 1999), o estudo das funções permite ao aluno adquirir a linguagem algébrica, a linguagem das ciências, permitindo várias conexões dentro e fora da própria Matemática.

Autores como Bassoi (2006), Ardenghi (2008), Delgado (2010) e Salgueiro (2011), pesquisaram acerca dos processos de ensino e de aprendizagem de função, fundamentando-se principalmente na Teoria de Registros de Representação Semiótica de Duval (2003), e obtiveram como resultado que a diversidade de registros de representação do mesmo objeto matemático, no caso, função, tem um papel relevante à compreensão dos estudantes. 
Considerando estes diferentes estudos e a pedagogia visual, foi elaborada uma primeira versão de uma Trajetória Hipotética de Aprendizagem (THA), pela pesquisadora (segunda autora deste artigo), na expectativa de identificar conhecimentos mobilizados por uma professora de estudantes surdos em uma escola bilíngue, ao desenvolver esta THA, em uma perspectiva construtivista.

\section{Pressupostos teóricos: Construtivismo e THA, conhecimentos à docência e Educação de Surdos}

Nesta pesquisa foi realizada uma primeira versão de uma THA, relacionada ao conteúdo de função afim, propondo atividades que podem ser abordadas de acordo com os princípios construtivistas, isto é, ser desenvolvida em grupo, considerando conhecimentos prévios dos estudantes, entre outros. No entanto, essa perspectiva depende de como é feito 0 desenvolvimento das atividades em sala de aula, pelo professor. Portanto, também foi discutida a relação entre THA e construtivismo, os conhecimentos à docência e a educação de estudantes surdos, visto que este é o público considerado no estudo.

\subsection{Construtivismo e THA}

Coll e Solé (2009) defendem o construtivismo como um referencial explicativo composto por diversas contribuições teóricas que auxiliam o professor nas ações que ocorrem no processo de ensino, tais como: planejamento, aplicação e avaliação do ensino. Partem da consideração social e socializadora da educação escolar em que se considera a reflexão da prática pedagógica de "como se aprende" e de "como se ensina", considerando o contexto dos sujeitos envolvidos.

Desta forma, o construtivismo não se trata de um manual e/ou receita que precisa ser seguida à risca sem considerar as especificidades de cada um. Ao contrário, esses autores afirmam a necessidade de teorias que contribuam com instrumentos de análise e reflexão sobre a prática, "teorias que podem e devem enriquecer-se infinitamente com contribuições acerca de como influem, nesta aprendizagem e no ensino" (COLL e SOLÉ, 2009, p. 12).

Segundo Coll e Solé (2009), o papel do professor não se limita a um "transmissor de informações", mas sim de mediador no processo de construção do conhecimento que propõe 
situações de ensino para a aprendizagem considerando a disponibilidade dos estudantes bem como seus conhecimentos prévios.

No que concerne à Matemática, Simon (1995) entende que a aprendizagem é um processo de construção individual e social em que o professor é o mediador de um trabalho estruturado que compreende a aprendizagem dos estudantes.

Para o autor, compreender o desenvolvimento da aprendizagem é essencial e a perspectiva construtivista está contribuindo nas reformas do ensino de Matemática. Ele usa 0 termo "Pedagogia da Matemática" para referir-se a todas as contribuições para a educação matemática na sala de aula, nas pesquisas educacionais e para o currículo.

Para expor sua proposta de Ciclo de Ensino de Matemática e de Trajetórias Hipotéticas de Aprendizagem, Simon (1995) busca relações entre construtivismo e pedagogia de Matemática. Para 0 autor, os professores precisam ter como finalidade a construção de uma prática que permita, a seus alunos, percorrerem o caminho da aprendizagem. No entendimento de Pires (2009, p. 10), "este é o desafio fundamental que deve fascinar os professores de Matemática, o que implica na necessidade de reconstruir meios para fazer conhecer a Matemática na escola e, deste modo, meios para ensinar Matemática", desta forma cabe ao professor desenvolver, junto aos estudantes, caminhos para a aprendizagem em uma perspectiva construtivista.

Simon (1995) compara a palavra trajetória com uma viagem. Quando uma pessoa faz uma viagem pelo mundo, por exemplo, há uma formulação de um plano para quais locais visitar primeiro, porém no caminho pode existir imprevistos, sendo necessário reformular o plano. 0 caminho pelo qual se viaja é, segundo o autor, a trajetória, e o caminho que tinha sido planejado é a trajetória hipotética.

Uma das características da THA é ter como hipótese os conhecimentos dos estudantes acerca do objeto matemático a ser estudado, que será confirmado ou não no desenvolvimento da mesma. Assim, a THA não é um processo estanque, na verdade é mutável, flexível e vai ao encontro das necessidades e especificidades dos estudantes em relação ao conteúdo a ser estudado. Portanto, ao elaborar a THA, a professora explicita seus conhecimentos em relação ao ensino da Matemática bem como constrói novos conhecimentos por meio das experiências vivenciadas. 
Simon (1995) desenvolveu o Ciclo de Ensino Matemático (Figura 1), o qual se trata de um modelo de inter-relações cíclicas dos aspectos do conhecimento do professor, objetivos, hipóteses e tomadas de atitudes.

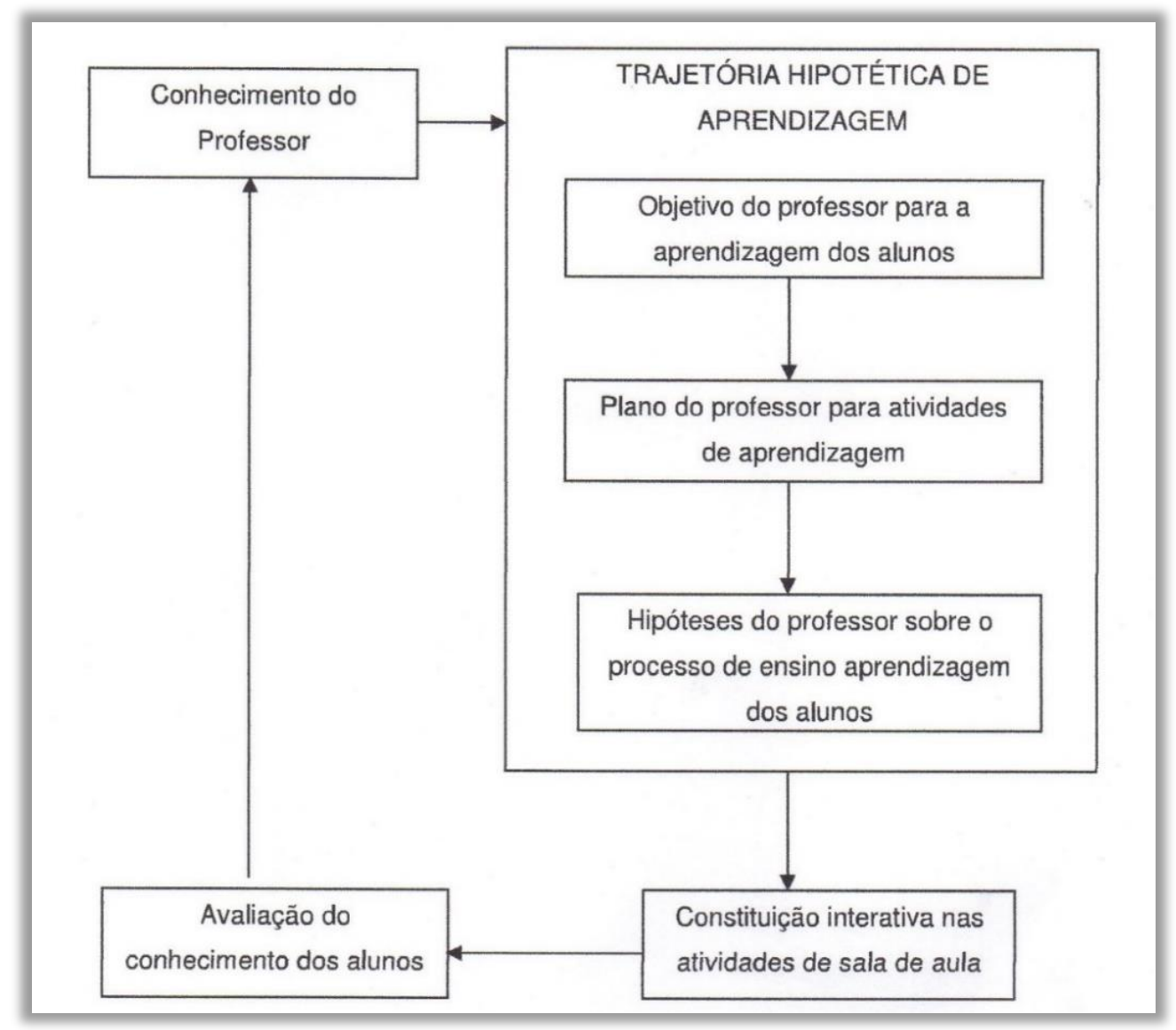

Figura 1: Ciclo de Ensino de Matemática Abreviado (SIMON, 1995, p. 136)

O objetivo de aprendizagem que o professor tem para seus alunos a partir das hipóteses estabelecidas é que norteia a trajetória hipotética de aprendizagem. A avaliação do pensamento do aluno no decorrer da THA pode trazer muitas mudanças e adaptações a respeito do conhecimento do professor, desta forma pode-se criar uma nova ou modificada a trajetória hipotética de aprendizagem.

\subsection{Conhecimentos à docência}

Há diversos pesquisadores, tais como Shulman (1986); Tardiff (2012); Gauthier et al. (1998), entre outros, que têm se dedicado aos estudos do desenvolvimento dos conhecimentos para a prática docente. Para esses autores, os professores precisam mobilizar diversos conhecimentos e ou saberes para transformar sua prática pedagógica. Desta forma, somente 0 
conhecimento específico da disciplina ministrada não consegue alcançar os objetivos do ensino e da aprendizagem.

Shulman (1986) afirmou haver falta de pesquisas sobre a forma como os professores explicar o conteúdo ou o porquê de escolherem determinada estratégia. Para 0 autor, os programas de pesquisa continuam a tratar o ensino de maneira genérica, não havendo a preocupação com o conteúdo específico do ensino. A partir da análise da complexidade do processo de compreensão do conhecimento do conteúdo pelos professores, ele propõe a diferenciação de três categorias no conhecimento do conteúdo para o ensino: conhecimento do conteúdo específico; conhecimento pedagógico do conteúdo e o conhecimento curricular.

Em relação ao conhecimento do conteúdo, Shulman (1986) afirma que esse vai além do conhecimento da área de estudo. É preciso que o professor compreenda os fatos, conceitos, processos de uma área específica de conhecimento além das relações do conteúdo com outras áreas, considerando aspectos específicos dos contextos em que leciona. Além disso, o professor precisa compreender por que um determinado tópico tem papel central ou periférico na disciplina.

O conhecimento pedagógico do conteúdo é, para Shulman (1986), uma categoria específica do conhecimento dos professores, que é a capacidade de transformar o conhecimento do conteúdo em formas pedagogicamente adaptadas a variações dos estudantes. É essa capacidade de transformação do conteúdo que difere um professor em relação a um especialista da matéria.

Dessa forma, o conhecimento pedagógico do conteúdo inclui as ilustrações, as comparações, os exemplos e as explicações para o ensino dos conteúdos específicos. Além disso, inclui a concepção prévia dos alunos considerando a faixa etária, a cultura e a classe social bem como a compreensão do propósito e estruturas de determinados conteúdos de maneira a facilitar os processos de ensino e de aprendizagem.

No que concerne ao conhecimento curricular, este precisa considerar o que foi aprendido nos anos anteriores pelos estudantes assim como o que vai ser visto nos anos posteriores. Além disso, é preciso programar os conteúdos considerando o ano em que o estudante se encontra bem como os materiais utilizados. Para isso, é essencial o conhecimento de softwares e materiais didáticos que vão ao encontro das necessidades do conteúdo específico e dos estudantes. 


\subsection{Educação para Surdos}

A situação das pessoas surdas foi marcada por momentos com preconceitos no decorrer da história da humanidade, conforme afirma Sá (2003, p. 89) ao destacar que "a situação a que estão submetidos os surdos, suas comunidades e suas organizações, no Brasil e no mundo, têm muita história de opressão para contar".

Segundo Dias (2006), até meados do século XVI as pessoas surdas eram vistas como ineducáveis e eram tidas até mesmo como loucas. Enfrentavam preconceito, piedade e descrédito sendo considerados inúteis para a sociedade.

A educação dos surdos teve em seu início duas vertentes: a médica e a religiosa. $\mathrm{Na}$ medicina despertava o interesse por ser considerada como uma deficiência relacionada à uma anomalia orgânica. Em relação à religião, a ajuda ao próximo fazia parte dos princípios dos padres, monges, entre outros, portanto se solidarizavam com as pessoas surdas.

Strobel (2009) afirma que, no Brasil, os primeiros relatos sobre a educação de surdos surgem somente em 1855, quando o professor francês Eduardo Huet (1712-1784), surdo, chega ao Brasil com a intenção de abrir uma escola para surdos. Em 1857, foi fundado no Rio de Janeiro o "Imperial Instituto dos Surdos-Mudos", sendo a primeira escola de surdos no Brasil, hoje conhecida como "Instituto Nacional de Educação de Surdos" (INES). Nesta escola, surgiu a Língua Brasileira de Sinais (LIBRAS), sendo esta uma mistura da língua de sinais francesa com os sistemas já usados pelos surdos de várias regiões do Brasil.

Há um embate histórico entre o método por meio de sinais e o método que prioriza a língua falada. O I Congresso Internacional sobre a Instrução de Surdos, que foi realizado no de ano de 1880 em Milão, Itália, influenciou por mais de um século as propostas educacionais para as pessoas surdas em muitos países do mundo, inclusive o Brasil. 0 objetivo era discutir a educação das pessoas surdas e contou com a participação de182 pessoas de vários países, sendo a maioria ouvintes. Neste congresso, o método oral (oralismo¹) foi declarado o mais adequado na educação dos surdos, o qual deveria ser o preferido em relação ao gestual, pois acreditava-se que as palavras eram superiores aos gestos (SILVA, 2006).

As conclusões do Congresso de Milão dividiram a história da educação dos surdos em dois períodos, segundo Skliar (1997), um período prévio em que eram comuns experiências

\footnotetext{
1 Oralismo é um método de ensino para surdos, defendido principalmente por Alexander Graham Bell (1874-1922),
} no qual se defende que a maneira mais eficaz de ensinar o surdo é por meio da língua oral, ou falada. 
educativas por meio da Língua de Sinais, e outro posterior em que a educação dos surdos se reduz à língua oral.

O posicionamento do Congresso, segundo Silva (2006), ocorreu pela crença no paradigma homem-máquina da ciência moderna, em que a surdez era vinculada à doença que necessitava de medicalização e de uma "pedagogia corretiva". A surdez era considerada um déficit biológico que podia ser curado, sendo as escolas os locais de tratamento dos surdos.

A partir do Congresso de Milão, o oralismo tornou-se um referencial para o ensino e a aprendizagem dos surdos, porém com resultados aquém do ideal. Segundo Silva (2006), a maior parte dos estudantes surdos mesmo com o uso de aparelho auditivo, teve muita dificuldade na aquisição da fala; quando conseguiam algum sucesso este era parcial e tardio.

No Brasil, o INES utilizou a Libras e o alfabeto manual até 1911 em que passou a adotar 0 oralismo, proibindo uso de sinais nas salas de aula (DIAS, 2006). A justificativa era o Congresso de Milão que norteava as ações educacionais dos surdos no nosso país e no mundo.

Até a década de 1980 não houve grandes avanços na educação dos surdos. Em junho de 1994, na Conferência Mundial sobre Necessidades Educativas Especiais: acesso e qualidade, foi elaborada a Declaração de Salamanca.

Neste documento é assegurado o direito fundamental à educação à toda criança, garantindo a oportunidade de atingir e manter o nível adequado de aprendizagem. A Declaração de Salamanca ressalta a importância de programas educacionais considerando a vasta diversidade, bem como características e necessidades de todas as crianças; 0 acesso à língua de sinais para todos os surdos enquanto necessidade particular de comunicação que precisa ser utilizada nas escolas.

A Lei de Diretrizes e Bases da Educação Nacional, Lei n. 9394/96 (BRASIL, 1996), foi norteada pela Declaração de Salamanca, garantindo assim o acesso a todas as pessoas à escola, assegurando a organização, os métodos e o currículo para atender as necessidades de todos os estudantes, eliminando as barreiras de acesso e permanência.

O documento "Política Nacional de Educação Especial" (BRASIL, 1994), publicado após a Declaração de Salamanca, tem como finalidade garantir o atendimento educacional às "pessoas portadoras de deficiência, condutas típicas e de altas habilidades" (p. 14), garantindo a integração dessas pessoas. 
O reconhecimento da Língua Brasileira de Sinais (Libras) ocorreu por meio da Lei Federal n. 10.4362 , de 24 de abril de 2002, regulamentada pelo Decreto $5.626^{3}$. Esse Decreto prevê a oferta da educação bilíngue para o surdo em todas as etapas escolares: da Educação Infantil ao Ensino Superior, considerando a Língua de Sinais como primeira língua e como segunda, a Língua Portuguesa.

De acordo com esse Decreto, os sistemas de ensino devem organizar escolas ou classes bilíngues para estudantes surdos e ouvintes. Quanto à formação inicial do professor, o decreto define a inclusão da disciplina Libras nos cursos de Licenciatura, iniciando, na época de sua publicação, em Pedagogia e Letras até universalizar em todos os cursos, incluindo fonoaudiologia e cursos de educação especial.

Aos professores que já estão em sala de aula, o Decreto coloca que as instituições de ensino devem viabilizar cursos de qualificação profissional ao quadro docente, bem como organizar o trabalho do tradutor e intérprete de Libras que atua em classes regulares com estudantes surdos.

Essas leis foram criadas como resultado de muitas lutas da Comunidade Surda, tornando a educação bilíngue um direito de todos os estudantes surdos, inserindo assim estes cidadãos na sociedade de maneira legítima.

Oliveira (2005), Borges (2006), Gil (2007), Nascimento (2009) e Neves (2011) realizaram pesquisas em relação à educação dos surdos nas quais enfatizam a necessidade da eliminação das barreiras de comunicação frequentes entre ouvintes e surdos, sendo essencial o domínio da Língua de Sinais para todos os professores destes estudantes. Cabe ressaltar que para Neves (2011), apenas o domínio de Libras por parte do professor não garante êxito nos processos de ensino e de aprendizagem.

Para Oliveira (2005) e Gil (2007), é necessário que o professor busque desenvolver a competência visual-espacial dos estudantes surdos por meio da utilização de materiais de manipulação e imagens.

\footnotetext{
2 BRASIL. Lei no 10436, de 24 de abril de 2002. Dispõe sobre a Língua Brasileira de Sinais - Libras e dá outras providências. Diário Oficial da União, Brasília, DF, 25 abril, 2002.

${ }^{3}$ Decreto $n^{0} 5626$, de 22 de dezembro de 2005. Regulamenta a Lei $n^{\circ}$ 10436, de 24 de abril de 2002, que dispõe sobre a Língua Brasileira de Sinais - Libras, e o art. 18 da Lei 10.098 de dezembro de 2002. Diário Oficial da União, Brasília, DF 23 dez. 2005.
} 
Referente à formação inicial do professor, Borges (2006) destaca que esta não é suficiente para preparar o futuro professor para atuar com as diferenças dos alunos, sejam elas intelectuais ou físicas.

A importância dos conhecimentos pedagógicos é destacada por Gil (2007). Para a autora, o professor precisa ter conhecimentos pedagógicos, didáticos e específicos, sendo que estes estão aquém do ideal quando se considera o trabalho diferenciado com os surdos. Já Neves (2011) defende que a formação de futuros professores deveria se basear na cultura e na identidade surda.

No que se refere ao processo avaliativo dos estudantes surdos, Gil (2007) destaca a necessidade de o professor considerar a Libras como primeira língua, sendo o português a segunda língua. Desta forma, avaliar somente por provas e atividades escritas não atende às particularidades dos surdos, sendo necessário considerar diversos instrumentos, no seu processo avaliativo, que contemplem a Língua de Sinais.

\section{Desenvolvimento da pesquisa}

A pesquisa realizada foi do tipo qualitativa, conforme definida por Bogdan e Biklen (1994). As características do estudo deste tipo de pesquisa são: a fonte direta de dados foi o ambiente natural de trabalho da professora pesquisada, na sala de aula de uma escola bilíngue; a pesquisa foi acompanhada constantemente pela pesquisadora, a fim de observar e compreender todas as ações ocorridas durante a produção dos dados; os dados consistem em transcrições de entrevistas, notas de campo, fotografias e vídeos; a pesquisa não teve como objetivo confirmar hipóteses construídas previamente; foram realizadas entrevistas semiestruturadas com a professora, antes e depois do desenvolvimento da THA, além disso a própria THA nos revelou concepções da professora, visto que ela foi reformulada a partir da experiência de ensino com estudantes surdos da própria professora; e aconteceram diálogos constantes entre a pesquisadora e a professora pesquisada durante a elaboração e desenvolvimento da THA.

Entre as diferentes pesquisas qualitativas, a pesquisa realizada tem, predominantemente, características do tipo de pesquisa-intervenção, que, de acordo com Rocha e Aguiar (2003, p. 66), "consiste em uma tendência das pesquisas participativas que busca investigar a vida de coletividades na sua diversidade qualitativa, assumindo uma intervenção de caráter socioanaltico". 
A pesquisa-intervenção vai ao encontro do objetivo deste estudo, por ser de abordagem qualitativa que trata das especificidades da Trajetória Hipotética de Aprendizagem contribuindo para a compreensão dos conhecimentos mobilizados pela professora no que concerne ao ensino do estudante surdo.

A investigação ocorreu em uma escola bilíngue em que uma professora, em particular, contribuiu junto à pesquisadora na realização e desenvolvimento de uma THA. A professora pesquisada reelaborou a Trajetória Hipotética de Aprendizagem a partir de uma versão proposta pela pesquisadora, bem como o desenvolvimento desta THA em uma turma do $9^{\circ}$ ano do Ensino Fundamental sobre os conceitos introdutórios de função.

A professora pesquisada é formada em Licenciatura em Matemática e Pedagogia. Também fez especialização em Educação Especial e, à época da pesquisa, cursava o Mestrado Profissional em Matemática (PROFMAT).

Na educação bilíngue, a professora tem experiência tanto nos anos iniciais quanto finais do Ensino Fundamental. Ela iniciou na EMEBs há 4 anos sem dominar a língua de sinais, que relata ser a realidade das EMEBs. A Prefeitura Municipal de São Paulo ofereceu um curso de formação continuada com duração de um ano, mas esse não teve a Matemática como foco.

Na EMEBs a professora tem uma sala ambiente para grupos pequenos, no máximo 11 alunos, que contém um computador com internet, data show e materiais didáticos. Borges (2006) ressalta a importância do ambiente pedagógico propício à aprendizagem do surdo, ambiente este encontrado na escola pesquisada.

As aulas da professora eram expositivas, com resolução de problemas e sequências didáticas. Ela utilizava o livro didático apenas para retirar conceitos, as estratégias utilizadas nas aulas eram elaboradas considerando sempre as imagens.

Quanto à avaliação, esta ocorria por meio de diversos instrumentos tais como: prova escrita (desenhos de figuras de apoio e gráficos, cálculos, frases com lacunas, entre outros), trabalho em grupo, trabalho individual, lição de casa, prova oral por sinais. Interessante notar que a professora valorizava a primeira língua dos estudantes surdos no processo avaliativo, coisa que, segundo Borges (2006), dificilmente ocorre com professores, mesmo os de escolas bilíngues. 


\section{Descrição e análise do estudo realizado}

A estratégia da professora em todas as atividades propostas foi inicialmente verificar se os estudantes compreendiam os enunciados das questões, que estavam escritos em língua portuguesa. A partir das dúvidas dos estudantes, a professora realizou as intervenções necessárias a fim de que compreendessem o significado do enunciado explicando o sentido em Libras.

Cabe ressaltar que a proposta inicial da THA era que os estudantes recebessem as atividades e, em grupo, as resolvessem, com algumas intervenções da professora. Porém, isto não foi possível, pois muitos alunos não compreenderam a língua portuguesa escrita nos enunciados. Este fato foi comentado diversas vezes pela professora, durante a elaboração da THA e corrobora a opinião dos autores apresentados na revisão bibliográfica tais como Oliveira (2005) e Neves (2011). Ambos ressaltam a importância da Língua de Sinais nos processos de ensino e de aprendizagem de Matemática para estudantes surdos.

Dentro deste contexto, a professora relatou as dificuldades apresentadas pelos estudantes surdos, dentre elas que muitas vezes os alunos conseguiam traduzir as palavras das frases, porém não compreendiam o contexto. Além disso, havia conceitos matemáticos que ainda não tinham sido codificados em Libras, o que demanda a criação de um sinal específico para aquele contexto. Houve preocupação constante da professora, não só com o conteúdo a ser ensinado, mas também com a articulação da Língua Portuguesa e da Libras, com a linguagem matemática, conforme aponta Neves (2011).

As preocupações da professora também iam ao encontro das propostas de Shulman (1987). Segundo o autor, conhecer o currículo como um todo, compreender aquilo que o estudante precisa saber para entender determinado conteúdo é imprescindível no processo de ensino. Para isso, é preciso conhecer as características dos estudantes, no caso de estudantes surdos, a forma como aprendem o vocabulário que possuem, se a surdez é congênita ou adquirida depois do desenvolvimento da fala, se são filhos de pais surdos ou ouvintes, entre outros.

A partir do conhecimento sobre a sua turma, bem como do repertório de seus alunos, a professora analisou a THA proposta a fim de modificar o que não estivesse de acordo com a realidade.

A THA era composta por quatro tarefas: regularidades, variação entre grandezas, construção do pensamento proporcional e dependência entre grandezas. Não houve mudanças 
significativas na THA, mas um fato que chamou a atenção é que na tarefa 1, nas atividades 1 e 2 , conforme seguem os Quadros 1 e 2, a professora solicitou mudanças nos itens, e e $f$, respectivamente:

Quadro 1: Tarefa 1, atividade 1

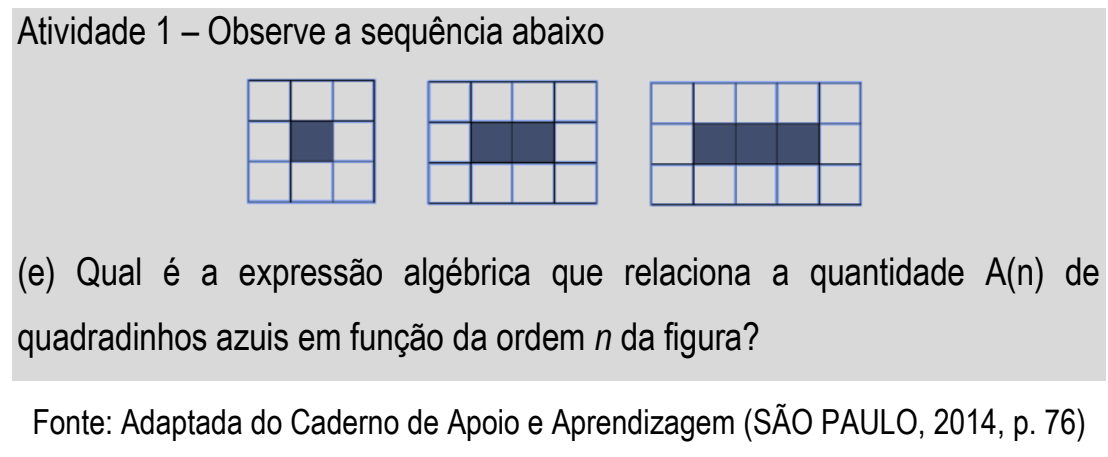

A professora solicitou que retirasse a palavra "algébrica" (Quadros 1 e 2), desconhecida pelos seus alunos. Mesmo estando no $9^{\circ}$ ano, estes estudantes ainda não tinham visto Álgebra por diversos fatores, segundo a professora, tais como: falta de professores preparados para ensinar Matemática para estudantes surdos, falta da apropriação da língua de sinais por alguns alunos, dúvidas básicas referentes aos anos iniciais do Ensino Fundamental, entre outros.

\section{Quadro 2: Tarefa 1, atividade 2}

Atividade 2 - Observe a sequência abaixo:

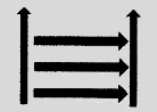

Etapa 1

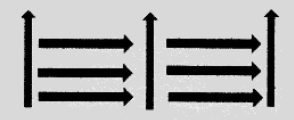

Etapa 2

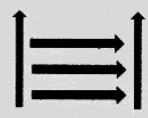

Etapa 3

(f) Escreva uma expressão algébrica que represente a situação acima

Fonte: Elaboração dos Autores

O fato descrito sobre a escolarização dos estudantes, corrobora com o processo histórico da Educação de Surdos descritos neste trabalho. Para Skliar (1997), esse processo foi marcado pela busca da cura do problema em vez de conhecimentos culturais do povo surdo como, por exemplo, a Língua de Sinais. Essa situação reflete na escola nos tempos atuais, visto que a regulamentação da Língua de Sinais e a Pedagogia Visual são recentes. Desta forma, a formação de professores habilitados para trabalhar com estes estudantes ainda está em processo.

Outro aspecto importante a ressaltar é em relação a THA. A professora fez poucas mudanças na tarefa 1, mas todas baseadas nas hipóteses de aprendizagem dos estudantes 
surdos, no vocabulário necessário para realizar as atividades, considerando os hipotéticos caminhos da aprendizagem.

Na tarefa 2, atividade 2 (Quadro 3), a professora disse que utilizaria como estratégia um teatro, uma dramatização, pois os surdos teriam a possibilidade de responder a questão dentro da sua língua, além de trabalhar com os aspectos visuais que são, segundo Campello (2008), essenciais nos processos de ensino e de aprendizagem dos estudantes surdos.

Quadro 3: Tarefa 2, atividade 2

Atividade 2

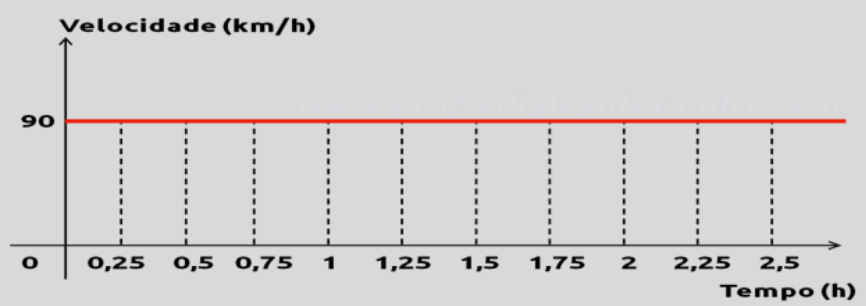

(b) Elabore uma situação-problema que se relacione com o gráfico.

Fonte: Adaptado pelos autores

Na atividade 3 da tarefa 2 (Quadro 4), a sugestão da professora foi os números decimais. Ela solicitou para usar a medida grama ao invés de quilograma para facilitar a compreensão dos estudantes, além de ganhar tempo, visto que o foco é o conceito introdutório de função e não os números decimais.

\section{Quadro 4: Tarefa 2, atividade 3}

Atividade 3 - Joana gosta de almoçar em dois restaurantes que ficam próximo do seu trabalho: "Preço Bom" e "Tudo Gostoso". No restaurante "Preço Bom" Joana pode se servir à vontade e paga um preço único de $R \$ 20,00$ pelas refeições. No restaurante "Tudo Gostoso" Joana paga $R \$ 2,50$ por $100 \mathrm{~g}$ de comida. Os gráficos abaixo representam a situação:

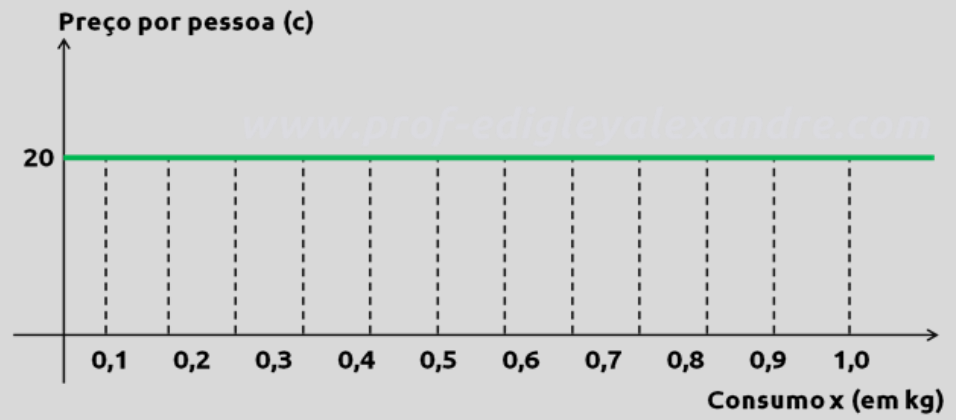




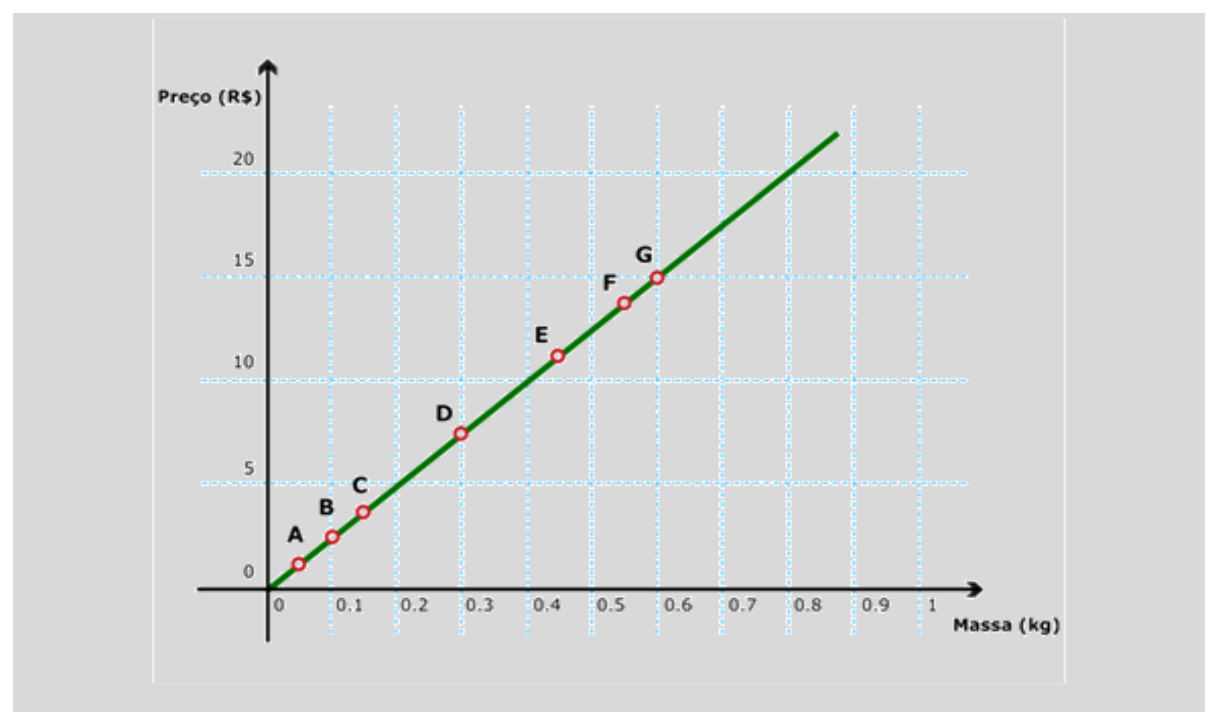

Fonte: Adaptação dos Autores

A atividade 4 da tarefa 2 não possuía nenhuma imagem; a professora questionou o porquê de não ter imagens. Foi explicado a ela que a elaboração da THA foi baseada na Teoria de Registros de Representação Semiótica e que a língua natural deveria estar presente. Como a língua natural dos estudantes surdos não é o português, essa atividade ficou inviável e foi retirada da THA. Cabe ressaltar que as ideias da professora vão ao encontro do que diz Campello (2008, p. 132), que "os signos da língua dos sujeitos Surdos possuem um caráter visual".

\subsection{Gestão da THA em sala de aula}

Ao iniciar as atividades da THA, a professora retomava às aulas anteriores e sempre fazia a tradução da Língua Portuguesa escrita para a Língua de Sinais coletivamente a fim de garantir que não houvesse dúvida no enunciado. Além disso, existia uma preocupação constante em ensinar palavras novas, que apareciam nos enunciados, aos estudantes.

Após a tradução, a professora deixava os estudantes realizar as atividades prestando atendimento individual quando solicitada, sem, entretanto, dar as respostas. Ao contrário, fazia questionamentos a fim de que os estudantes alcançassem o objetivo. Outro ponto a destacar é que os estudantes dificilmente chamavam a professora para esclarecer dúvidas, estes se levantavam o tempo todo em direção à lousa para fazer as perguntas.

Outra situação que a professora precisava dar conta era em relação à disputa dos estudantes. Além deles se levantarem constantemente da mesa, sem serem solicitados, muitas 
vezes ficavam bravos uns com os outros e discutiam sobre quem estava certo. A professora precisava acalmá-los para conseguir prosseguir a aula.

Uma estratégia utilizada pela professora foi a sistematização das tarefas. Depois de acompanhar os estudantes na resolução das atividades, se dirigia à lousa para fazer a correção coletivamente. Desta forma, permitiu aos estudantes a participação, a socialização das dúvidas e das conjecturas que ocorreram durante a resolução.

No que concerne ao tempo previsto, este não foi adequado para a maioria das atividades. O tempo gasto na atividade 1, da tarefa 1, foi excessivo, o que limitou o desenvolvimento da THA. Assim, não foi possível desenvolver todas as atividades propostas.

A partir deste fato podemos afirmar que, ao desenvolver as atividades, ainda estava imbricado na pesquisadora uma perspectiva mais tradicional em alguns momentos, no entanto, na maioria das atividades prevaleceu a abordagem construtivista, isto é, a professora atuou como mediadora entre o conhecimento e os estudantes. Houve momentos do desenvolvimento da THA em que a professora agiu de maneira tradicional, este comportamento vai ao encontro do que diz CHARLOT (2008, p. 25): "podemos deduzir que a função do professor não é apenas acompanhar os alunos em processos construtivistas, mas também, de forma mais "tradicional", pôr em circulação significações desconhecidas pelo aluno".

\subsection{Organização da sala de aula}

A organização da sala de aula se dava em "U", pois esta posição favorece a visualização das imagens colocadas na sua frente, bem como a comunicação em Língua de Sinais e as discussões coletivas. Cabe ressaltar que a participação de todos se deveu ao fato de a sala ter somente 10 estudantes, mas o nível de participação dos alunos era diferenciado.

O controle da turma foi mantido pela professora. No entanto, devido à forma de organização da sala, foi possível que estes estudantes interagissem entre si, em diferentes momentos. Em algumas situações, andavam pela sala de aula para poder se comunicar melhor. A professora utilizava-se da estratégia de piscar a luz, quando queria chamar a atenção deles. 


\subsection{Estratégias de ensino}

A professora mostrou domínio do conteúdo específico de Matemática, tanto nos momentos de tirar dúvidas individuais dos estudantes quanto naqueles que era necessário fazer fechamentos coletivos.

Os estudantes mostraram-se muito dependentes da professora para realizar as atividades propostas, principalmente na compreensão dos enunciados em língua portuguesa. Em relação ao conhecimento matemático, as dúvidas e equívocos cometidos eram os mesmos que estudantes ouvintes cometem.

Em alguns momentos, a professora não conhecia o sinal do termo, utilizou a estratégia da datilologia para explicar a palavra. Em relação aos significados das palavras, Gómez-Granell (1997) afirma que em um contexto geral seu significado é vago e impreciso, porém na linguagem matemática as palavras são específicas, exatas e formais. Assim, entende-se ser muito importante que os estudantes, surdos ou ouvintes, compreendam o significado dos termos usados na Matemática.

Para explicar os questionamentos dos estudantes, a professora sempre buscava exemplos concretos a fim de sanar dúvidas, geralmente utilizava imagens e figuras colocadas na lousa. Campello (2008) afirma ser necessário uma pedagogia específica para os surdos, pois eles aprendem de maneira diferente dos ouvintes.

A professora utilizou-se da estratégia de simular representações de peças de teatro em algumas situações de aprendizagem. Ela convidava os estudantes para irem à frente fazer a interpretação dos contextos. Os estudantes participavam das situações propostas pela professora com entusiasmo.

O aspecto visual durante as aulas foi imprescindível para que os estudantes compreendessem os comandos. Para Campello (2008, p. 205), "a visualidade contribui, de maneira fundamental, para a construção de sentidos e significados".

\subsection{Análise dos acertos e erros das atividades pela professora}

Após o desenvolvimento da THA, a professora pesquisada analisava as respostas dos estudantes para fazer uma reflexão do que eles compreenderam para reconstruir a prática da 
próxima aula. Na primeira atividade da tarefa 1 (Quadro 5), algo chamou a atenção da professora.

Todos haviam acertado a resposta, porém três alunas chegaram à ela de uma maneira peculiar.

Quadro 5: Tarefa 1, atividade 1

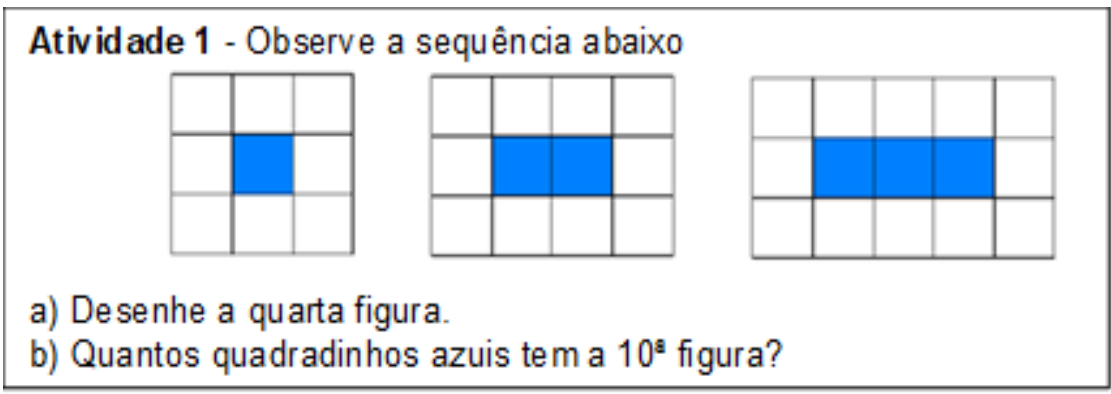

Fonte: Atividade adaptada do Caderno de Apoio e Aprendizagem (SÃO PAULO, 2014, p. 76)

Pelas respostas colocadas, a professora teve como hipótese de que o obstáculo foi a língua, as estudantes não compreenderam o enunciado. A dificuldade apresentada pelas estudantes foi no item b da atividade acima. Segue o trecho:

Professora pesquisada: Para dar 10 elas somaram os quadradinhos azuis das 4 primeiras figuras, por isso 1+2+3+4 e deu 10. E esse 10, ignora a comanda, suponhamos que a comanda seja azul, quando soma azul da 10, na verdade qual seria a formação, a conta de que dá 10. Então o que elas fizeram, somaram $1+2+3+4=10$, é esse 10 que está aqui, então está certo o exercício. Foi isso que uma pensou e convenceu as colegas de que era assim.

Pesquisadora: O que você vai fazer?

Professora pesquisada: Explicar qual é a comanda do exercício, porque elas entenderam que era uma somatória das sequências. Inclusive até a quarta figura porque o item a, elas poderiam ter somado aí não daria 10, ai daria conflito nesse item $b$.

Pesquisadora: Uma forma delas entenderem, é você mostrar o conflito. Dá certo para todos?

Professora pesquisada: Não, porque se eu fizer isso vou mudar o 10 que está aqui, aí para ela será outra comanda.

Pesquisadora: Porque pensei assim, elas estão falando que precisava somar as anteriores para chegar na resposta 10, certo? Então você pergunta, mas esta forma de fazer funciona para todas as figuras?

Professora pesquisada: Mas eu acredito que elas não enxergam isso como uma regra de formação.

Pesquisadora: Então você acha que essa dificuldade foi na questão da língua, ela não entendeu a comanda?

Professora pesquisada: Isso.

(Trecho do dia 01 set. 2016) 
$\mathrm{Na}$ aula seguinte a professora retomou a atividade com as estudantes, explicando o enunciado de uma maneira diferente da aula anterior. As alunas então perceberam o erro e conseguiram realizar a atividade. A dificuldade era de fato na língua. Campello (2008, p. 144), afirma que "os sinais visuais não são apenas palavras por palavras (sinais por sinais) e sim um complexo semântico, sintático e fonético (quirema), pragmático com suas sutilezas dentro da comunicação".

Para Shulman (1986), a base do conhecimento para o ensino inclui conhecer os alunos e suas características e foi este conhecimento que permitiu, à professora pesquisada, compreender a real dificuldade das estudantes. Mas isso não foi percebido no desenvolvimento da THA, foi preciso uma reflexão após a aula para a professora compreender a situação e, então, reformular a próxima ação, partindo das dificuldades dos estudantes.

O estudo do conteúdo do ensino e a maneira como esses conteúdos são transformados em ensino, faz parte da base de conhecimentos do professor. No caso da professora de surdos, a transformação do conteúdo específico para o ensino passa por outro desafio, a apropriação da língua de sinais bem como sua relação com a língua portuguesa.

\section{Considerações}

Por meio dos critérios de análise pudemos observar os conhecimentos mobilizados pela professora. Ao elaborar a THA partindo de uma atividade proposta pela pesquisadora, não houve grandes modificações pelo fato de a professora não estar habituada a elaborar trajetórias hipotéticas de aprendizagem, ou seja, atividades elaboradas de acordo com objetivos, hipóteses de aprendizagem e conhecimentos dos alunos. Porém, no desenvolvimento, ficou clara a preocupação dela em adequar a THA às necessidades dos estudantes.

Sendo assim, já é possível anunciar um conhecimento que a professora de estudantes surdos mobilizou no processo antes da aula, que é o de adaptar as atividades já existentes para a realidade da sua sala de aula. De acordo com a professora, sua tarefa de preparação de aula é mais de adaptação de atividades do que de criação.

Outro conhecimento mobilizado, relevante no processo analisado, é a articulação feita entre a Língua Portuguesa, Libras e Linguagem Matemática presente na prática da professora em diferentes momentos. Mesmo que a professora não seja fluente em Libras, o seu domínio além do 
básico contribuiu muito com os processos de ensino de aprendizagem. Este resultado vai ao encontro do que afirma Neves (2011), ao considerar que os professores de estudantes surdos precisam articular de maneira plena a Língua Portuguesa, a Língua de Sinais e a Linguagem Matemática.

Outro conhecimento mobilizado pela professora é o de saber avaliar os seus estudantes. Quando os objetivos das atividades não eram alcançados, ela realizava modificações, acrescentando exercícios, encenações e utilizava-se de recursos visuais para explicar de forma diferente, o mesmo conteúdo.

Também vale destacar a característica construtivista da professora, citada por Coll e Solé (2009). Em relação às mediações das atividades, a professora, quando questionada, procurava responder de maneiras diferentes considerando as dificuldades dos estudantes. Os estudantes estavam acostumados a levantar hipóteses e questionar resultados. Sempre que possível, a resposta da professora era em forma de outra questão que colocava o aluno para refletir e descobrir suas próprias dúvidas.

O olhar reflexivo e analítico da professora durante e depois das aulas permitiram que 0 ciclo proposto por Simon (1995) fosse realizado. Apesar de, segundo Campello (2008), não existir uma sistematização de conhecimentos especializados para nortear a formação de docentes de estudantes surdos, a professora mostrou bastante conhecimento em relação aos estudantes. Temos, como hipótese, que isso se deveu ao fato de a professora conhecer os estudantes da turma, além de suas competências matemáticas, mas também a cultura desta comunidade.

Dentro deste contexto, ainda são necessários muitos estudos no que concerne aos conhecimentos mobilizados por um professor de estudantes surdos. Além de formação específica para os professores, de materiais condizentes às necessidades destes estudantes, é preciso eliminar a barreira da comunicação.

Desta forma, podemos afirmar que a THA contribuiu para compreender os conhecimentos mobilizados pela professora de estudantes surdos, considerando que a professora pesquisada possui formação específica e experiência com a educação de surdos. Também mostrou a falta de experiência da pesquisadora, pois trouxe uma sequência de atividades muito extensa desconsiderando as possíveis dificuldades dos estudantes. Essa situação mostra que não há atividade perfeita, pronta, que serve para todos os estudantes; é preciso considerar as 
características específicas de cada um e isso só é possível de ser realizado pelo professor da turma.

\section{Referências}

ARDENGHI, Marcos José. Ensino-aprendizagem do conceito de função: pesquisas realizadas no período de 1970 a 2005 no Brasil. 2008. 182f. Dissertação (Mestrado em Educação Matemática) - Faculdade de Ciências Exatas e Tecnologias. Pontifícia Universidade Católica de São Paulo. São Paulo.

BASSOI, Tânia Stella. Uma professora, seus alunos e as representações do objeto matemático funções em aulas do Ensino Fundamental. 2006. 182f. Tese (Doutorado em Educação) - Setor de Educação. Universidade Federal do Paraná. Curitiba.

BOGDAN, Roberto Carlos; BIKLEN, Sari Knopp. Investigação qualitativa em Educação. Tradução Maria João Alvarez, Sara Bahia dos Santos e Telmo Mourinho Baptista. Porto: Porto Editora, 1994.

BORGES, Fábio Alexandre. Institucionalização (sistemática) das representações sociais sobre a "deficiência" e surdez: relações com o ensino de Ciências e Matemática. 2006. 164f. Dissertação (Mestrado em Educação para a Ciência e o Ensino de Matemática). Universidade Estadual de Maringá. Maringá.

BRASIL. Lei n. 9.394, de 20 de dezembro de 1996. Estabelece as diretrizes e bases da educação nacional. Brasília: Diário Oficial da União, 20 dez. 1996.

BRASIL. Ministério da Educação. Secretaria de Educação Básica. Parâmetros Curriculares Nacionais - Ensino Médio: Ciências da Natureza, Matemática e suas Tecnologias. Brasília: MEC/SEB, 1999.

BRASIL. Ministério da Educação. Secretaria de Educação Especial. Política Nacional de Educação Especial. Brasilia: MEC/SEESP, 1994.

CAMPELLO, Ana Regina e Souza. Aspectos da visualidade na educação de surdos. 2008. $245 f$. Tese (Doutorado em Educação) - Centro de Ciências da Educação. Universidade Federal de Santa Catarina, Florianópolis, 2008.

CHARLOT, B. Um professor na sociedade contemporânea: um trabalho da contradição. Educação e Contemporaneidade, Salvador, v. 17, n. 30, p. 17-31, jul./dez. 2008.

COLL, Cesar; SOLÉ, Isabel. Os professores e a concepção construtivista. In: COLL, Cesar. (Org.). O construtivismo na sala de aula. Tradução de Claudia Schilling. São Paulo: Ática, 2009.

DELGADO, Carlos José Borges. O ensino da função afim a partir dos registros de representação semiótica. 2010. 153f. Dissertação (Mestrado em Ensino das Ciências na Educação Básica) Escola de Educação, Ciências, Letras, Artes e Humanidades. Universidade do Grande Rio. Duque de Caxias. 
DIAS, Tárcia Regina da Silveira. Educação de surdos na escola pública e bilinguismo. V CONGRESSO INTERNACIONAL DO INSTITUTO NACIONAL DE EDUCAÇÃO DE SURDOS E IX Seminário Nacional do Instituto Nacional de Educação de Surdos. Anais do V CIINES e IX SNINES: Surdez: família, linguagem, educação. 2006.

DUVAL, Raymond. Registros de representações semióticas e funcionamento cognitivo da compreensão em Matemática. In: MACHADO, Silvia Dias Alcântara. (Org.). Aprendizagem em Matemática: registros de representação semiótica. Campinas: Papirus, 2003, p. 11-33.

GAUTHIER, Clermont; MARTINEAU, Stéphane; DESBIENS, Jean-François; MALO, Annie; SIMARD, Denis. Por uma teoria da Pedagogia: pesquisas contemporâneas sobre o saber docente. ljuí: Unijuí, 1998.

GIL, Rita Sidmar Alencar. Educação Matemática para surdos: um estudo das necessidades formativas dos professores que ensinam conceitos matemáticos no contexto de educação de deficientes auditivos em Belém/PA. 2007. 191f. Dissertação (Mestrado em Educação em Ciências e Matemática) - Instituto de Educação Matemática e Científica. Universidade Federal do Pará. Belém.

GÓMEZ-GRANELL, Carmen. A aquisição da linguagem: símbolo e significado. In: TEBEROSKY, Ana; TOLCHINSKI, Liliana. (Org.). Além da alfabetização: a aprendizagem fonológica, ortográfica, textual e matemática. Tradução de Stela Oliveira. São Paulo: Ática, 1997, p. 257-282.

NASCIMENTO, Paulo Roberto do. Uma proposta de formação do professor de Matemática para a educação de surdos. 2009. 89f. Dissertação (Mestrado em Ensino de Ciências e Matemática). Centro Federal de Educação Tecnológica Celso Suckow da Fonseca. Rio de Janeiro.

NEVES, Maria Janete Bastos da. A comunicação em Matemática na sala de aula: obstáculos de natureza metodológica na educação de alunos surdos. 2011. 131f. Dissertação (Mestrado em Educação em Ciências e Matemática) - Instituto de Educação Matemática e Científica. Universidade Federal do Pará. Belém.

OLIVEIRA, Janine Soares de. A comunidade surda: perfil, barreiras e caminhos promissores no processo de ensino-aprendizagem em Matemática. 2005. 78f. Dissertação (Mestrado em Ensino de Ciências e Matemática). Centro Federal de Educação Tecnológica Celso Suckow da Fonseca. Rio de Janeiro.

PIRES, Célia Maria Carolino. Perspectivas construtivistas e organizações curriculares: um encontro com as formulações de Martin Simon. Educação Matemática Pesquisa, São Paulo, v. 11, n. 1 p. 145-166, jan./jun. 2009.

ROCHA, Marisa Lopes da; AGUIAR, Katia Faria de. Pesquisa-intervenção e a produção de novas análises. Psicologia: Ciência e Profissão, Brasília, v. 23, n. 4, p. 64-73, dez. 2003.

SÁ, Nidia Regina Limeira de. Convite a uma revisão da pedagogia para minorias: questionando as práticas discursivas na educação de surdos. Espaço, Rio de Janeiro, n. 18/19, p. 87-93, 2003.

SALGUEIRO, Nilton Cesar Garcia. Como estudantes do ensino médio lidam com registros de representação semiótica de funções. 2011. 132f. Dissertação (Mestrado em Ensino de Ciências e 
Educação Matemática) - Centro de Ciências Exatas. Universidade Estadual de Londrina. Londrina.

SÃO PAULO (Município). Secretaria Municipal de Educação. Diretoria de Orientação Técnica. Caderno de Apoio e Aprendizagem: Matemática, $8^{\circ}$ ano, Livro do Professor. São Paulo: SME/DOT, 2014.

SHULMAN, Lee S. Knowledge and teaching: foundations of a new reform. Harvard Educational Review, v. 57, n. 1, p. 1-22, apr. 1987.

SHULMAN, Lee S. Those who understand: knowledge growth in teaching. Educational Researcher, v. 15, n. 4, p. 4-14, feb. 1986.

SILVA, Vilmar. Educação de surdos: uma releitura da primeira escola pública para surdos em Paris e do Congresso de Milão em 1880. In: QUADROS, Ronice Müller de. (Org). Estudos surdos I. Petrópolis: Arara Azul, 2006. p. 14-37.

SIMON, Martin A. Reconstructing Mathematics Pedagogy from a Constructivist Perspective. Journal for research in Mathematics Education, v. 26, n. 2. p. 114-145, mar. 1995.

SKLIAR, Carlos B. (Org). Educação e exclusão: abordagens socioantropológicas em Educação Especial. Mediação, 1997.

STROBEL, Karin Lilian. História da educação dos surdos. Florianópolis: UFSC, 2009.

TARDIF, Maurice. Saberes docentes e formação profissional. 13. ed. Tradução de Francisco Pereira de Lima. Petrópolis: Vozes, 2012. 